\title{
An Automatically Queuing and Positioning Technology Based on Conveyor Belt
}

\author{
Ma Ziling ${ }^{*}$ and Hao Yongxing
}

North China University of Water Resources and Electric Power, Zhengzhou, Henan, 450045, P.R. China

\begin{abstract}
In order to reduce complexity of a manipulator system for grabbing and locating a product shaped like a mobile phone, with uncertain position and posture on the conveyor belt, an automatically queuing and positioning technology has been proposed, which can implement the functions of product storage, queuing and positioning. By analyzing the application environment, mobile phones' automatic queuing solutions are proposed, and theoretical models regarding mobile phones' automatic queuing are designed. Using non-fixed point collision theory based on rigid body dynamics, collision models between the phone and the phones' automatically queuing mechanical device model and between two phone are analyzed, and the collision equations are deduced. The simulation analyses for all kinds of automatically queuing solutions for are implemented based on ABAQUS. The results show that multi-adaptive V-groove can queue and position the mobile phone with uncertain position and posture efficiently and automatically.
\end{abstract}

Keywords: ABAQUS simulation, Auto queuing and positioning, Manipulator, Rigid body collision.

\section{INTRODUCTION}

A manipulator is good at moving objects from a fixed position to another fixed position, but has greater difficulty to directly move the objects with uncertain position and posture. Aiming at the problem, the common practice is to first use some kind of method to fix the objects on a fixed position and then move them. In mobile phone production line as the research background, a technology automatically queuing and positioning products shaped like a mobile phone with uncertain position and posture is researched.

Currently, the production line of testing of the overall unit of the mobile phone mainly relies on the manpower that picks up the phone to place on testing equipment for testing. After the process, the manpower puts the phone back onto the conveyor belt to flow to the next detection process. Due to the rising labor costs, some factories have started to use Multi-DOF (Degree of Freedom) manipulator and testing equipment to replace manpower. But because of high cost and technical complexity, the Multi-DOF manipulator does not have the ability to grab the moving mobile phone with uncertain position and posture directly from the conveyor belt, which still needs manpower to complete the grabbing of the mobile phone and placing of it onto a specialized mobile phone tray according to the demand of fixed position and posture for the multi-DOF manipulator grabbing. In order to replace the work of this staff, according to the ideas of the function of modularization, decentralization and equalization, an intelligently positioning mobile phone manipulator system with low DOF, low cost and good maintainability has been developed to provide mobile phone positioning services for the multi-DOF manipulator. The

*Address correspondence to this author at the School North China University of Water Resources and Electric Power, Zhengzhou, Henan, 450045, P.R. China; Tel: +86 13233806855; E-mail: zlma2008@qq.com intelligent positioning mobile phone manipulator system consists of mobile phone automatically queuing module, visual servo module and manipulator module of completing the action of grabbing and placing. This paper focuses on the mobile phones' automatically queuing module, which can implement the functions of mobile phones storage, queuing and positioning before mobile phones are captured by the manipulator module. The work of the mobile phones' automatically queuing module is conducive for the manipulator module to capture the mobile phones.

\section{MOBILE PHONES' AUTOMATICALLY QUEUING SCHEME}

Mobile phones moving forward on the conveyor belt, are positioned randomly by the production worker. The transported products shape is length $\mathrm{a}=110 \mathrm{~mm}$, width $\mathrm{b}=$ $60 \mathrm{~mm}$, thickness $\mathrm{c}=10 \mathrm{~mm}$, mass $\mathrm{m}=120 \mathrm{~g}$. The material of the shell is PC (Poly Carbonate) and the Modulus of elasticity $\mathrm{E}=2300 \mathrm{Mpa}$. The speed of conveyor belt is $\mathrm{V}=6$ $\mathrm{m} / \mathrm{min}$, with the width of the conveyor belt being $\mathrm{B}=500$ $\mathrm{mm}$. The coefficient of friction between the phones is 0.05 and the coefficient of friction between the belt and the phone is 0.3 . As the mobile phones' positions are not in order and not fixed, the difficulty of capturing phones for manipulator has been greatly increased. Therefore, it has been considered to design a V-groove (whose function is shown in Fig. 1) to position these irregularly placed phones (as in Fig. 1a) and give them a uniform direction (as in Fig. (1b) after passing through the $\mathrm{V}$-groove. The $\mathrm{V}$-groove can reduce the number of DOF manipulators to capture the phones when needed.

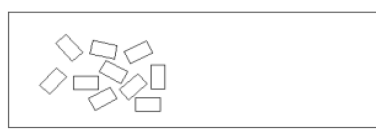

(a)

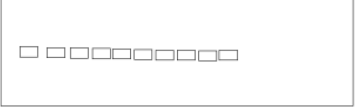

(b)
Fig. (1). V-groove's function. 
Solution (1): The ordering of phones by fixed V-groove device. As shown in Fig. (2), a fixed V-groove and a guide groove are placed on a conveyor belt. A few mobile phones with a specific position can get through by ABAQUS software simulation, but a large number of specially located phones can extrude the V-groove and pile up there without passing through, thereby proving this scheme unfeasible.

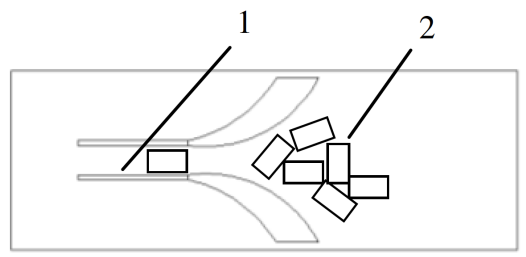

1- Guide-groove 2- Fixed V-groove

Fig. (2). The ordering of phones by fixed V-groove device

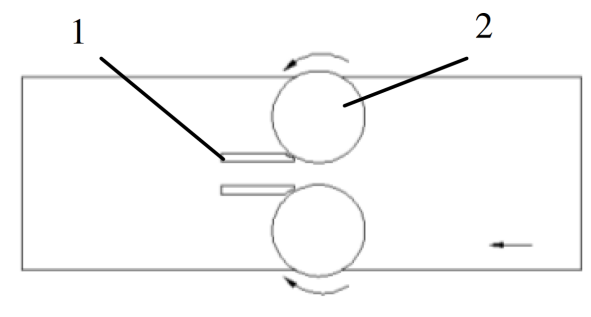

1- Guide-groove 2- Roller

Fig. (3). Anti-extrusion V-groove device

Solution (2): The ordering of phones by anti-extrusion Vgroove device. It is assessed that an anti-extrusion device should be used if the irregularly located mobile phones are to be passed through the V-groove smoothly from the solution (1). As shown in Fig. (3), the device consists of a pair of symmetrical placement rollers and a guide groove. The cambered surface of the counter rotating device which is toward the incoming materials, forms an anti-extrusion Vgroove together with the conveyor belt [1]. Direction of the rotating rollers and the movement direction of the conveyor belt are shown in Fig. (3). Through the ABAQUS simulation, it has been found that the large number of specially located phones can pass through the V-groove smoothly by continuously adjusting the speed of the two rollers.

Solution (3): The ordering of phones by the multiadaptability V-groove device. It is known that the large quantity of specially located phones can smoothly get through the V-groove by adjusting the speed of the rollers. However, varied rotating speeds are required for different situations. For example, as in Fig. (4a), only when the gap between the rotating speeds of two rollers is large and has reached more than 3.5 times, then can these phones pass through rapidly; however in Fig. (4b), only when the differences of the rotating speed between two rollers are relatively small, then these phones can pass through smoothly. For the situation shown in Fig. (1a), it is required to constantly observe the position of phones in the V-groove and to continuously adjust the speed ration of the two rollers to make phones get through successfully, which greatly increases the difficulty level for monitoring and controlling. Nevertheless, in the process of making simulation analysis with ABAQUS software, it is observed that the phones can pass most easily when they are away from the centerline of the conveyor belt. Based on this, a guide post can be fixed on the center line of the conveyor belt to separate the mobile phone flow with purpose to make the phones close to the edge of the roller as much as possible, as illustrated in Fig. (5).

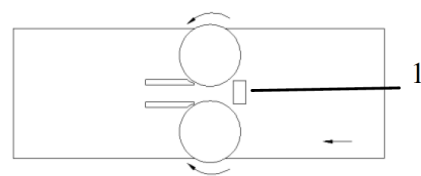

(a)

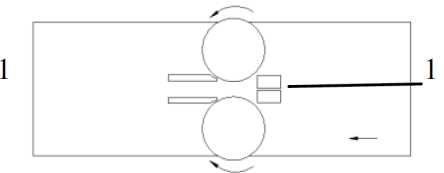

(b)

\section{1-Mobile phone}

Fig. (4). Phones ordered by anti-extrusion V-groove device.

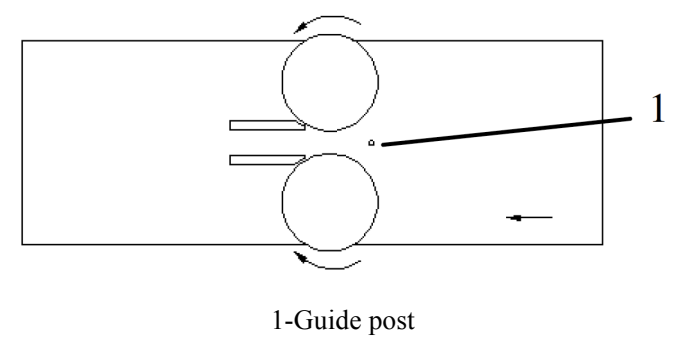

Fig. (5). Multi-adaptive V-groove device.

\section{MOBILE PHONE COLLISION THEORY MODEL}

For the simulation of movement of mobile phone through various $\mathrm{V}$-grooves, theoretical analysis needs to be carried out for mobile phone collision process. As to simplify the problem, and in consideration of the actual situation, it can be assumed that the actual contact area in the process of mobile phone collision does not have normal and tangential distortion [2], which belongs to rigid contact. So, the mobile phone collision can be simplified as rigid body non-fixed point external impact [3]. For the convenience of analysis, the shape of the mobile phone is simplified into a cuboid, and the rollers are simplified into a cylinder, so the collision model between the mobile phone and the rollers is shown in Fig. (6a), and the collision model between mobile phone and mobile phone is shown in Fig. (6b). The collision between the phone and the guide post and the collision between the phone and the V-groove are similar to the collision between the mobile phone and the rollers.

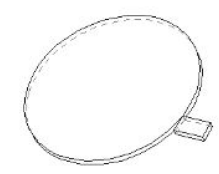

(a)

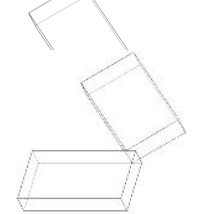

(b)
Fig. (6). The collision model in V-groove.

To study the mobile phone collision motion law [2] using the momentum balance method (discretization method), for the collision phenomenon and system, it can be assumed that [4]: 1) Collision process is completed instantaneously. The collision process has greater impact force and the ordinary force of elastic force and gravity cannot be compared with it, 
so the momentum of these common forces is negligible; 2) Collision contact surface is very small, which can be regarded as a line segment; collision deformation is within a very small range based on the line segment; 3) The displacement of the object is negligible in the collision process; 4) The impact of friction is not considered during the collision; 5) Before and after the collision, all objects' geometry and inertia parameters are unchanged; 6) Recovery coefficient only depends on the material, which is regardless of the local and overall geometry of the object, the size of the speed and the tangential velocity. Here, the recovery coefficient is 1 [5].

\subsection{Mathematical Model of Collision Between Mobile Phone and Roller}

The collision model between the mobile phone and the rollers is shown in Fig. (7); rectangular plane coordinate system is established in the center (Point P) of the collision zone, and the model is simplified as the collision between rectangle $\mathrm{ABCD}$ and arc surface. Before the collision, the speed of the barycenter of rigid body $M$ (which is the mobile phone, whose barycenter is $\mathrm{M}$ ) is $\overline{\mathrm{V}_{\mathrm{M}}}$, and the angular velocity is $\mathrm{W}_{\mathrm{m} 0}$. After the collision speed, the speed of barycenter of rigid body $\mathrm{M}$ is $\overline{\mathrm{V}_{\mathrm{M}}^{\prime}}$ and the angular velocity is $\mathrm{W}_{\mathrm{m} 1}$. The quality of the rigid body is $\mathrm{m}$, the length is a, the width is $b$ and the moment of inertia is $J=\frac{1}{12} \mathrm{~m}\left(\mathrm{a}^{2}+\mathrm{b}^{2}\right)$. The collision equations in rigid body plane motion are.

$\mathrm{m} \overrightarrow{\mathrm{V}}_{\mathrm{Mx}}^{\prime}-\mathrm{m} \overrightarrow{\mathrm{V}}_{\mathrm{Mx}}=\sum \mathrm{I}_{x}$

$\mathrm{m} \overrightarrow{\mathrm{V}}_{\mathrm{My}}^{\prime}-\mathrm{m} \overrightarrow{\mathrm{V}}_{\mathrm{My}}=\sum \mathrm{I}_{\mathrm{y}}$

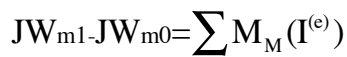

Because the contact collision is frictionless, only the Ydirection collision momentum $\mathrm{I}_{y}$ is considered, $\mathrm{I}_{x} \mathrm{I}_{\mathrm{x}}=0$ 。 As the rigid body undergoes plane motion, we can get:

$\overrightarrow{\mathrm{V}_{\mathrm{C}}}=\overline{\mathrm{V}_{M}}+\overline{\mathrm{V}_{\mathrm{CM}}}, \overline{\mathrm{V}_{\mathrm{C}}^{\prime}}=\overline{\mathrm{V}_{M}^{\prime}}+\overline{\mathrm{V}_{\mathrm{CM}}^{\prime}}$

And because

$\mathrm{V}_{\mathrm{My}}=\mathrm{V}_{\mathrm{M}}, \quad \mathrm{K}=\left|\frac{\overrightarrow{\mathrm{V}_{\mathrm{C}}^{\prime}}}{\overline{\mathrm{V}_{\mathrm{C}}}}\right|=1$

According to Equation (1)-(5), we can deduce

$$
\begin{aligned}
& \mathrm{W}_{\mathrm{m} 1}=\frac{12 \mathrm{~V}_{\mathrm{M}} \cos \beta+\left(3 \cos ^{2} \beta-1\right) \mathrm{Wm}_{\mathrm{m} 0} \sqrt{\mathrm{a}^{2}+\mathrm{b}^{2}}}{\left(3 \cos ^{2} \beta+1\right) \sqrt{\mathrm{a}^{2}+\mathrm{b}^{2}}} \\
& \mathrm{~V}_{\mathrm{My}}^{\prime}=\frac{\mathrm{V}_{\mathrm{M}}+\mathrm{W}_{\mathrm{m} 0} \sqrt{\mathrm{a}^{2}+\mathrm{b}^{2}} \cos \beta-3 \mathrm{~V}_{\mathrm{M}} \cos ^{2} \beta}{3 \cos ^{2} \beta+1}
\end{aligned}
$$

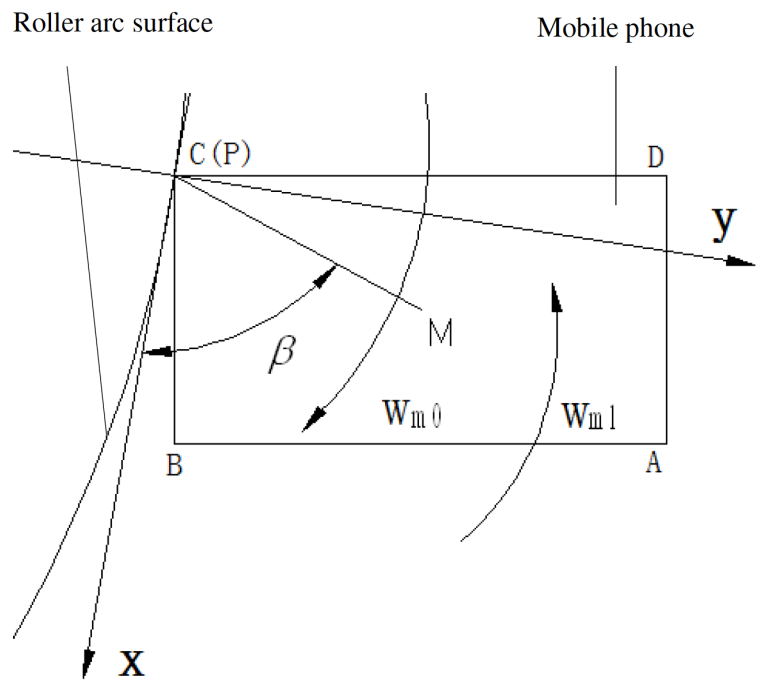

Fig. (7). Mathematical model of collision between mobile phone and roller.

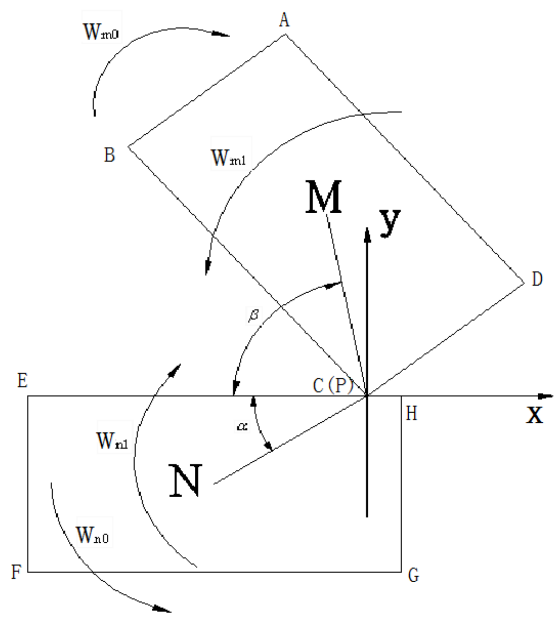

Fig. (8). Mathematical model of collision between mobile phone and mobile phone.

\subsection{Mathematical Model of Collision Between Mobile Phone and Mobile Phone}

The collision model between two mobile phones is shown in Fig. (8); rectangular plane coordinate system is established in the center (Point P) of the collision zone, and the model is simplified as the collision between rectangle $\mathrm{ABCD}$ and rectangle $\mathrm{EFGH}$, whose barycenters are $\mathrm{M}$ and $\mathrm{N}$. Before the collision, the speed of barycenter of rigid body $\mathrm{M}$ (which is one mobile phone) is $\overline{\mathrm{V}_{\mathrm{M}}}$, the angular velocity is $\mathrm{W}_{\mathrm{m} 0}$, the distance between collision point and barycenter is $\mathrm{L}_{1}$; the speed of barycenter of rigid body $\mathrm{N}$ (which is one mobile phone) is $\overrightarrow{\mathrm{VN}_{\mathrm{N}}}$, the angular velocity is $\mathrm{W}_{\mathrm{n} 0}$, and the distance between collision point and barycenter is $\mathrm{L}_{2}$. After collision speed, the speed of barycenter of the rigid body $\mathrm{M}$ is $\overline{\mathrm{V}_{\mathrm{M}}^{\prime}}$, the angular velocity is $\mathrm{W} \mathrm{m} 1$, the speed of barycenter of rigid body $\mathrm{N}$ is $\overline{\mathrm{V}_{\mathrm{N}}^{\prime}}$, and the angular velocity is $\mathrm{W}_{\mathrm{n} 1}$. The quality of the two rigid bodies is $\mathrm{m}$, the length is a, the 
width is $\mathrm{b}$ and the moment of inertia is $\mathrm{J}=\frac{1}{12} \mathrm{~m}\left(\mathrm{a}^{2}+\mathrm{b}^{2}\right)$. The collision process is as follows:

According to the law of conservation of momentum:

$\mathrm{m} \overline{\mathrm{V}_{\mathrm{M}}}+\mathrm{m} \overline{\mathrm{V}_{\mathrm{N}}}=\mathrm{m} \overline{\mathrm{V}_{\mathrm{M}}^{\prime}}+\mathrm{m} \overline{\mathrm{V}_{\mathrm{N}}^{\prime}}$

According to the theorem of impulse moment:

$\mathrm{JW}_{\mathrm{m} 1-\mathrm{JW} 0}=\sum \mathrm{M}_{\mathrm{M}}\left(\mathrm{I}^{(\mathrm{e})}\right)$

$\mathrm{JWn} 1-\mathrm{JWn} 0=\sum \mathrm{M}_{N}\left(\mathrm{I}^{(\mathrm{e})}\right)$

According to the theorem of impulse:

$\mathrm{m} \overline{\mathrm{V}_{\mathrm{M}}^{\prime}}-\mathrm{m} \overline{\mathrm{V}_{\mathrm{M}}}=\sum \mathrm{I}_{\mathrm{M}}^{(\mathrm{e})}$

$\mathrm{m} \overrightarrow{\mathrm{V}_{\mathrm{N}}^{\prime}}-\mathrm{m} \overrightarrow{\mathrm{V}_{\mathrm{N}}}=\sum \mathrm{I}_{\mathrm{N}}^{(\mathrm{e})}$

According to Newton's recovery coefficient [6]:

$\mathrm{K}=\left|\frac{\overrightarrow{\mathrm{V}_{\mathrm{C}}^{\prime}}-\overrightarrow{\mathrm{V}_{\mathrm{P}}^{\prime}}}{\overline{\mathrm{V}_{\mathrm{C}}}-\overline{\mathrm{V}_{\mathrm{P}}}}\right|=1$

According to the theorem of kinetic energy:

$\frac{1}{2} \mathrm{JW}_{\mathrm{m} 0}^{2}+\frac{1}{2} \mathrm{mV}_{\mathrm{M}}^{2}+\frac{1}{2} \mathrm{JW}_{\mathrm{n} 0}^{2}+\frac{1}{2} \mathrm{mV}_{\mathrm{N}}^{2}=\frac{1}{2} \mathrm{JW}_{\mathrm{m} 1}^{2}+\frac{1}{2} \mathrm{mV}_{\mathrm{M}}^{\prime 2}+\frac{1}{2} \mathrm{JW}_{\mathrm{n} 1}^{2}+\frac{1}{2} \mathrm{mV}_{\mathrm{N}}^{\prime 2}$

As it is a smooth contact collision, only the Y-direction collision momentum $\mathrm{I}_{y}$ is considered i.e., $\mathrm{I}_{x} \mathrm{I}_{\mathrm{x}}=0$ 。 The rate in the $\mathrm{X}$ direction remains unchanged before and after the collision.

Moreover,

$\overline{\mathrm{I}_{\mathrm{M}}^{(\mathrm{e})}}=-\overline{\mathrm{I}_{\mathrm{N}}^{(\mathrm{e})}}$

$\overrightarrow{\mathrm{V}_{\mathrm{C}}}=\overrightarrow{\mathrm{V}_{\mathrm{M}}}+\overrightarrow{\mathrm{V}_{\mathrm{CM}}}$

$\overline{\mathrm{V}_{\mathrm{C}}^{\prime}}=\overline{\mathrm{V}_{\mathrm{M}}^{\prime}}+\overline{\mathrm{V}_{\mathrm{CM}}^{\prime}}$

$\overrightarrow{\mathrm{V}_{\mathrm{P}}}=\overrightarrow{\mathrm{V}_{\mathrm{N}}}+\overrightarrow{\mathrm{V}_{\mathrm{PN}}}$

$\overrightarrow{\mathrm{V}_{\mathrm{P}}^{\prime}}=\overrightarrow{\mathrm{V}_{\mathrm{N}}^{\prime}}+\overrightarrow{\mathrm{V}_{\mathrm{PN}}^{\prime}}$

Thus, according to Equation (8)-(19), we can calculate

$$
\begin{aligned}
\mathrm{W}_{\mathrm{m} 1}= & \frac{\left(\mathrm{mL}_{2}^{2} \cos ^{2} \alpha+2 \mathrm{~J}-\mathrm{mL}_{1}^{2} \cos ^{2} \beta\right) \mathrm{W}_{\mathrm{m} 0}}{\left(\mathrm{~mL}_{2}^{2} \cos ^{2} \alpha+2 \mathrm{~J}+\mathrm{mL}_{1}^{2} \cos ^{2} \beta\right)} \\
& +\frac{2 \mathrm{~mL}_{1} \cos \beta\left(\mathrm{V}_{\mathrm{M}}+\mathrm{V}_{\mathrm{N}}\right)+2 \mathrm{~mL}_{1} \mathrm{~L}_{2} \cos \alpha \cos \beta \mathrm{W}_{\mathrm{n} 0}}{\left(\mathrm{~mL}_{2}^{2} \cos ^{2} \alpha+2 \mathrm{~J}+\mathrm{mL}_{1}^{2} \cos ^{2} \beta\right)}
\end{aligned}
$$

$$
\begin{aligned}
\mathrm{W}_{\mathrm{n} 1}= & \frac{\left(\mathrm{mL}_{1}^{2} \cos ^{2} \beta+2 \mathrm{~J}-\mathrm{mL}_{2}^{2} \cos ^{2} \alpha\right) \mathrm{W}_{\mathrm{n} 0}}{\left(\mathrm{~mL}_{1}^{2} \cos ^{2} \beta+2 \mathrm{~J}+\mathrm{mL}_{2}^{2} \cos ^{2} \alpha\right)} \\
& +\frac{2 \mathrm{~mL}_{2} \cos \alpha\left(\mathrm{V}_{\mathrm{M}}+\mathrm{V}_{\mathrm{N}}\right)+2 \mathrm{~mL}_{1} \mathrm{~L}_{2} \cos \alpha \cos \beta \mathrm{W}_{\mathrm{m} 0}}{\left(\mathrm{~mL}_{1}^{2} \cos ^{2} \beta+2 \mathrm{~J}+\mathrm{mL}_{2}^{2} \cos ^{2} \alpha\right)}
\end{aligned}
$$

$\mathrm{V}_{\mathrm{M}}^{\prime}=\frac{\mathrm{JW}_{\mathrm{m} 1}-\mathrm{JW}_{\mathrm{m} 0}}{\mathrm{~mL}_{1} \cos \beta}+\mathrm{V}_{\mathrm{M}}$

$\mathrm{V}_{\mathrm{N}}^{\prime}=\frac{\mathrm{JW}_{\mathrm{n} 1}-\mathrm{JW}_{\mathrm{n} 0}}{\mathrm{~mL}_{2} \cos \alpha}+\mathrm{V}_{\mathrm{N}}$

The barycenter speed and the angular velocity after the two mobile phones collide can be obtained according to the above conditions and so the movement path can be determined.

\subsection{Law of Motion After the Collision}

Mobile phone status after the collision: Translation and rotation (As in Fig. 9), the barycenter speed $v_{0}$ and the angular velocity $w_{0}$ are known. The coefficient of friction between the mobile phone and the plane is $\downarrow$.

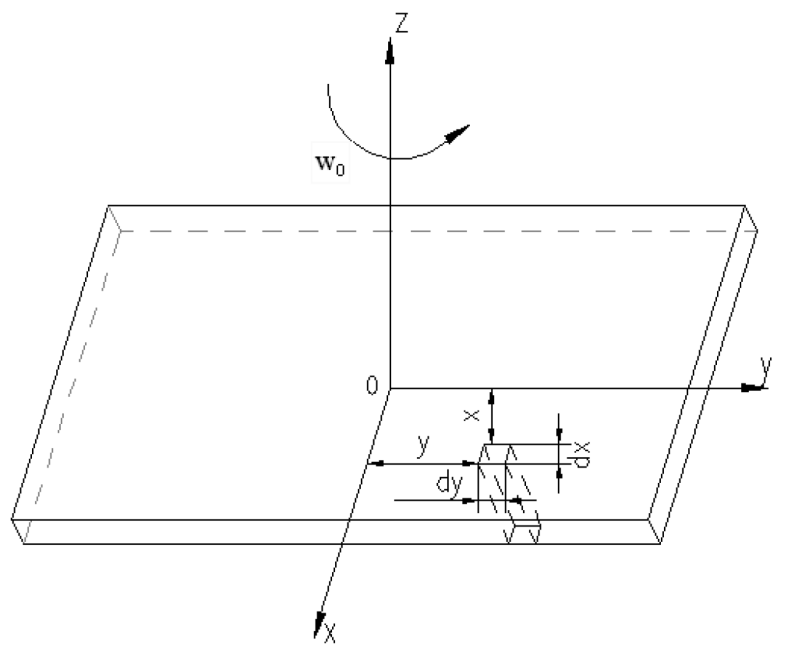

Fig. (9). Motion model after mobile phone collision.

1. For translational motion: On the plane to make uniform deceleration, the change relationship of the speed can be obtained as

$\mathrm{V}_{\mathrm{t}}=\mathrm{V}_{0}-\mathrm{g} \mu \mathrm{t}$

2. For rotational movement around the $\mathrm{z}$ axis as shown in Fig. (9), a rectangular figure unit with length dy and width $\mathrm{dx}$ is calculated.

The friction that the figure unit suffered is

$\mathrm{df}=\mu \mathrm{dN}=\mu \mathrm{gdm}=\mu \mathrm{gm} \frac{\mathrm{dxdy}}{\mathrm{ab}}$

The torque that the figure unit suffered relative rotation is

$\mathrm{dM}=\sqrt{\mathrm{x}^{2}+\mathrm{y}^{2}} \mathrm{df}$

The total torque that the physical block suffered is

$M=\int d M=\frac{\mu g m}{a b} \int_{-\frac{a}{2}}^{\frac{a}{2}} \int_{-\frac{b}{2}}^{\frac{b}{2}} \sqrt{x^{2}+y^{2}} d x d y$

Assuming that the rotation time of mobile phone is $t$. According to angular momentum theorem, there is 
$\int_{0}^{\mathrm{t}} \mathrm{Mdt}=\mathrm{JW}_{0}$

\section{THE SIMULATION AND VERIFICATION OF THE MULTI-ADAPTIVE V-GROOVE TO QUEUE AND POSITION MOBILE PHONE}

In the above paragraphs, the simulated effects of Solution (1) and Solution (2) are explained. Here, the effectiveness of the Solution (3) with good expected effect is verified.

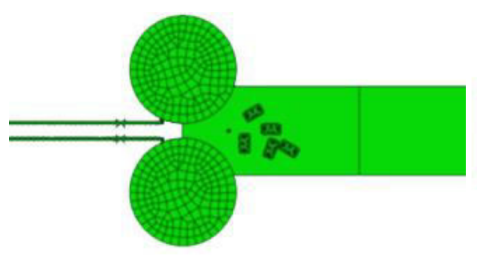

(a)

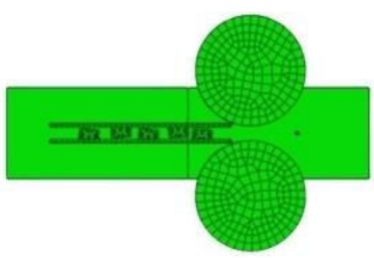

(b)
Fig. (10). Simulation verification by ABAQUS.

On the premise of setting roller speed as a fixed value, the result of using ABAQUS software modeling and simulation is shown in Fig. (10), the model parameters are shown in Table $\mathbf{1}$ and the friction coefficients between each component are shown in Table 2. Fig. (10) (a) and (b) show that: When the flow is high, specially positioned mobile phone passing through the multi-adaptive v-groove (Solution (3)), can not only achieve the purpose of queuing and positioning the mobile phone, but also eliminate the issue that the anti-extrusion V-groove needs to constantly adjust rollers speed because the rotational speed of each of the two rollers is fixed. Therefore, this scheme is feasible. In addition, ABAQUS software simulation shows that the program is highly adaptable for a variety of conditions, as shown in Fig. (4), Fig. (1a) and other special locations.

But a large number of simulations show that: The time of mobile phone passing through the $\mathrm{V}$-groove changes with two roller speed adjustment. When one roller velocity is fixed, the relationship between the time of the mobile phone through the $\mathrm{V}$-groove and the roller velocity ratio is as shown in Fig. (11); when the roller speed ratio is fixed, the relationship between the time of the mobile phone through the $\mathrm{V}$-groove and the roller velocity with larger velocity is as shown in Fig. (12). In addition, ABAQUS software simulation shows that: The distance between the guide post and the roller edge should not be too great. If the phone is more diagonally placed, it will not be able to serve as a good guide and direct the following phones in a proper direction. Therefore, the optimized model operating speeds are shown in Table 3.

To further facilitate the work of manipulator grabbing, a baffle can be added at the end of the guide groove, as shown in Fig. (13). After adding the baffle, the queued phone is stored in the guide groove. Whenever grabbing is to be proceeded, the manipulator just goes on to grab the phone close to the baffle. After the phone close to the baffle is taken, the phone stored in the guide groove moves forward into the mobile phone's location, so that another phone stays close to the baffle in the guide groove to wait for next grabbing. This allows the manipulator to grab the phone each time at a fixed position, which reduces the complexity of the manipulator greatly and helps reduce the systemscost and improve systems maintenance.

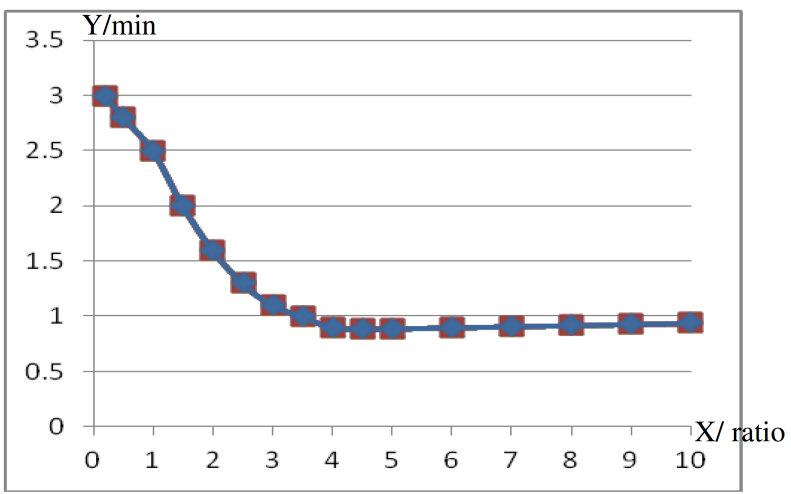

Fig. (11). The relationship between transit time and the roller velocity ratio.

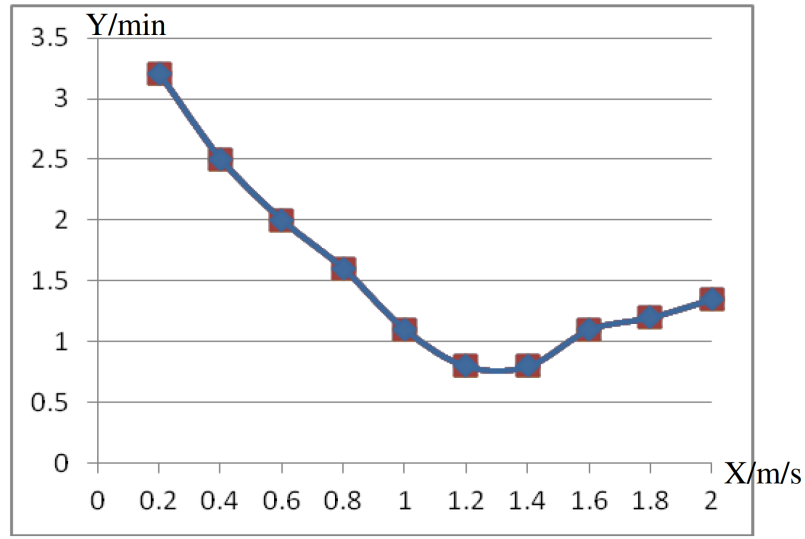

Fig. (12). The relationship between transit time and roller speed in a certain speed ratio.

Table 1. Model parameters

\begin{tabular}{|c|c|c|c|c|c|c|}
\hline & Diameter & Length & Width & Height & Material & Modulus of Elasticity \\
\hline \hline Roller & $0.6 \mathrm{~m}$ & & & $0.12 \mathrm{~m}$ & PA & $70 \mathrm{MPA}$ \\
\hline Conveyor belt & & $2 \mathrm{~m}$ & $0.5 \mathrm{~m}$ & $0.1 \mathrm{~m}$ & PVC & \multicolumn{2}{|c|}{ PC } \\
\hline Mobile phone & & $0.11 \mathrm{~m}$ & $0.06 \mathrm{~m}$ & $0.02 \mathrm{~m}$ & PC & $2300 \mathrm{MPA}$ \\
\hline Guide groove & & $1 \mathrm{~m}$ & $0.08 \mathrm{~m}$ & $0.05 \mathrm{~m}$ & PC & $2300 \mathrm{MPA}$ \\
\hline Guide post & $0.02 \mathrm{~m}$ & & & $0.05 \mathrm{~m}$ & & PCA \\
\hline
\end{tabular}


Table 2. The coefficient of models.

\begin{tabular}{|c|c|c|c|c|c|c|}
\hline & Mobile Phone & Roller1 & Roller2 & Guide Post & Guide Groove & Conveyor Belt \\
\hline \hline Mobile phone & 0.05 & 0.4 & 0.4 & 0.05 & 0.05 & 0.3 \\
\hline
\end{tabular}

According to the relevant parameters mentioned above, three-dimensional entity model of a multi-adaptive $\mathrm{V}$-groove device is designed, as shown in Fig. (14). Among them, additive special product tray, manipulator, camera and its holder are for maintaining the function relationship between them and the multi-adaptive $\mathrm{V}$-groove device.

Table 3. The operating speed of models.

\begin{tabular}{|c|c|c|c|}
\hline & Roller1 & Roller2 & Conveyor Belt \\
\hline \hline Operating speed & $0.08 \mathrm{rad} / \mathrm{s}$ & $0.3 \mathrm{rad} / \mathrm{s}$ & $0.1 \mathrm{~m} / \mathrm{s}$ \\
\hline
\end{tabular}

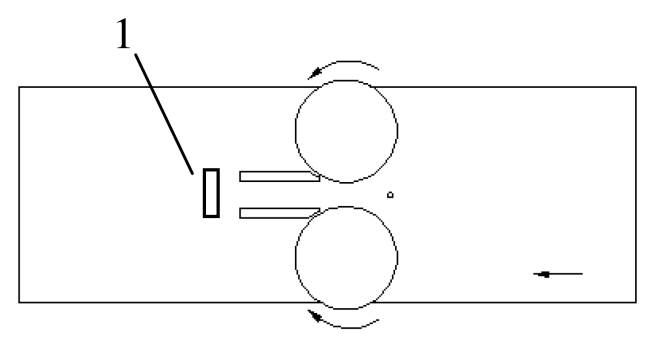

1- Baffle

Fig. (13). Multi-adaptive v-groove with a baffle.

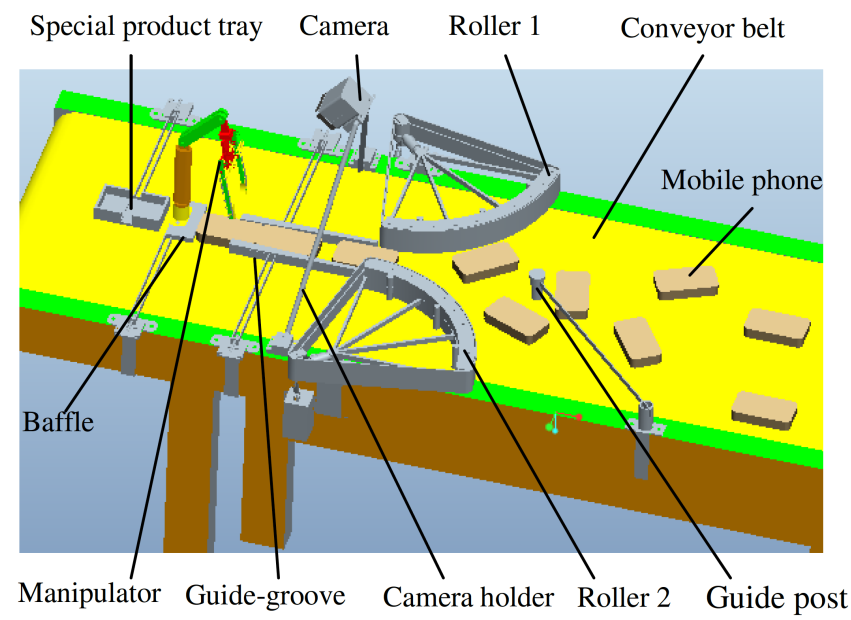

Fig. (14). Three-dimensional entity model of a multi-adaptive Vgroove device.

\section{CONCLUSION}

This paper mainly studied on how to queue and position the products shaped like a mobile phone with uncertain position and posture automatically when they move on the conveyor belt. In the mobile phone production line as the research background, using kinetic knowledge, the external impact of the kinetic equations of mobile phones' non-fixed point and the kinetic equations after the collision of mobile phone were deduced. Using ABAQUS software to simulate and analyze the model, the feasibility of the multi-adaptive $\mathrm{V}$-groove to queue and position the mobile phone was determined. It was observed that the program could make the original chaotic phone to have unified direction and fixed position. The study not only provides a method for automatically queuing and positioning products shaped like a mobile phone with uncertain position and posture on the conveyor belt, but also reduce the cost of products and the operation difficulty of the manipulator greatly.

\section{CONFLICT OF INTEREST}

The author confirms that this article content has no conflict of interest.

\section{ACKNOWLEDGEMENTS}

Declared none.

\section{REFERENCES}

[1] Y. X. Hao, Z. L. Ma, and L. F. Li, “Auto Arrange Mechanism of Products, " China Patent, 10292864.0, 2013.

[2] L. L. Gao, "Researching The Kinematics and Dynamics of The Rigid Body System with Non-fixed Point Collision", MS thesis, Shandong University of Science and Technology, China, 2011.

[3] W. G. Jiang, and D. G. Zhang, "The equations of internal impacted dynamics in multi-rigidbody system," Noise and Vibration Control, no.3, pp. 17-19, 2000.

[4] Theoretical Mechanics Teaching and Research Office of Harbin Institute of Technology, Theoretical Mechanics, Higher Education Press, China, pp. 1-235, 2009.

[5] M. Liang, J. Z. Hong, and Y. Z. Liu, "Impact kinetic equation and solvability criterion for multi-rigidbody system," Chinese Journal of Applied Mechanics, vol. 8, no. 1, pp. 56-63, 1991.

[6] J. Z. Zhang, "Application condition of recovery coefficient formula for general motion rigid body", Mechanics in Engineering, vol. 32, no. 3, pp. 116-117, 2010 . 